\title{
PEER COUNSELING COACHING TENTANG KEHAMILAN TIDAK DIINGINKAN (UNWANTED PREGNANCY) DI KALANGAN REMAJA TINGKAT SEKOLAH MENENGAH KEJURUAN SE-KECAMATAN PLAYEN, GUNUNG KIDUL, YOGYAKARTA
}

\author{
Oleh: \\ Siti Muyana dan Ulfa Danni Rosada \\ Email: siti.muyana@bk.uad.ac.id \\ Email: ulfa.rosada@bk.uad.ac.id
}

\begin{abstract}
Ringkasan
Kehamilan tidak diinginkan (unwanted pregnancy) dikalangan remaja khususnya siswa harusnya tidak terjadi, oleh karena itu penting adanya upaya pencegahan melalui pemberian informasi dan pelatihan bagi siswa untuk dapat menyikapi dengan baik teman sebayanya yang ingin berbagi. Oleh sebab itu siswa perlu dilatih untuk dapat menjadi konselor sebaya yang terampil dan berwawasan luas tentang bahaya kehamilan tidak diinginkan (unwanted pregnancy). Konseling sebaya (peer counseling) merupakan suatu wahana belajar remaja untuk dapat saling memperhatikan dan saling bantu satu sama lain. Konseling sebaya secara kuat menempatkan keterampilanketerampilan komunikasi untuk memfasilitasi eksplorasi diri dan pembuatan keputusan. Pengabdian masyarakat ini diberikan dengan menggunakan metode ceramah dan praktik atau demonstrasi. Subyek pengabdian merupakan siswa-siswi sekolah menengah kejuruan di kecamatan Playen Gunung Kidul yang berjumlah 70 peserta didik. Hasil pelaksanaan pengabdian pada masyarakat terlihat perubahan pemahaman peserta pelatihan terkait dengan pengetahuan kehamilan tidak diinginkan (unwanted pregnancy) baik penyebab dan dampak negatifnya dan keterampilan yang harus dimiliki peer counselor dalam melaksanakan layanan peer counseling. Tujuan akhir dari pelaksanaan pegabdian melalui pemberian pemahaman dan pelatihan ini agar remaja dapat meningkatkan pemahaman pengetahuan kehamilan tidak diinginkan (unwanted pregnancy) dan menguasai keterampilan konseling yang berguna untuk membantu teman sebaya yang sedang menghadapi permasalahan.
\end{abstract}

Kata kunci: peer counseling, kehamilan tidak diinginkan.

\begin{abstract}
Unwanted pregnancy among teenagers, especially students should not happen, therefore it is important to prevent prevention through the provision of information and training for students to be able to respond well to peers who want to share. Therefore students need to be trained to be able to be a skilled and knowledgeable peer counselor about the dangers of unwanted pregnancies. Peer counseling is a vehicle for adolescent learning to be able to care for each other and help each other. Peer counseling strongly places communication skills to facilitate self-exploration and decisionmaking. This community service is given by using lecture and practice or demonstration methods. Subjects in this service are students of vocational high school in the subdistrict of Playen Gunung Kidul, amounting to 70 students. The results of the implementation of community service are seen as a change in the understanding of the participants related to the unwanted pregnancy knowledge of both the causes and the negative impacts and skills that peer counselors must possess in implementing peer counseling services. The ultimate goal of pegabdian implementation through the provision of this understanding and training so that adolescents can improve understanding of unwanted pregnancy knowledge and mastering counseling skills that are useful to help peers who are facing problems.
\end{abstract}

Keyword: Peer Counseling, Unwanted Pregnancy 


\section{A. PENDAHULUAN}

Masa remaja merupakan suatu masa yang menjadi bagian dari kehidupan manusia yang di dalamnya penuh dengan dinamika. Dinamika kehidupan remaja ini akan sangat berpengaruh terhadap pembentukan diri remaja itu sendiri. Masa remaja dapat dicirikan dengan banyaknya rasa ingin tahu pada diri seseorang dalam berbagai hal, tidak terkecuali dalam bidang seks. Seiring dengan bertambahnya usia, organ reproduksi seseorang akan mengalami perkembangan yang pada akhirnya akan mengalami kematangan. Salah satu permasalahan yang sering timbul terkait dengan masa awal kematangan organ reproduksi pada remaja adalah pemahaman terhadap prilaku seks yang seringkali keliru. Orang dulu menganggap bahwa seks merupakan hal yang tabu untuk dibicarakan dan hanya dapat dilakukan setelah menikah. Saat ini, membicarakan seks sudah dianggap sebagai sesuatu yang wajar, akan tetapi prilaku seks pranikah justru terkesan sebagai sesuatu yang sudah tidak asing lagi dikalangan remaja dan bahkan hingga terjadi kehamilan tidak diinginkan.

Pentingnya pemahaman terhadap seks yang benar diharapkan dapat menanggulangi masalah kehamilan tidak diinginkan yang terjadi pada remaja di luar pernikahan. Lebih jauh lagi jika kehamilan tersebut terjadi pada usia sekolah mengingat betapa besar akibat yang akan ditimbulkan. Meskipun demikian, masih banyak timbul pedebatan antara setuju dan tidak jika pendidikan seks diberikan pada siswa baik di sekolah maupun di masyarakat. Hal tersebut dapat dilihat dari pendapat Mendiknas (Antara News: 2010) yaitu "pendidikan seks tidak perlu menjadi salah satu kurikulum di sekolah karena seks adalah bisa tumbuh dan muncul secara alamiah tanpa harus diajarkan”. Berdasarkan pernyataan tersebut dapat diperoleh kesimpulan bahwa, secara alamiah pengetahuan mengenai seks akan diketahui peserta didik, tanpa harus adanya pendidikan khusus atau kurikulum yang mengajarkan mengenai seks. Seiring dengan hal tersebut pendidikan seks juga dianggap sebagai pendorong remaja untuk melakukan hubungan seks.

Agar remaja dapat memenuhi perkembangan seks secara tepat maka dibutuhan pemahaman yang benar terhadap kehamilan tidak diinginkan. Pemahaman mengenai kehamilan tidak diinginkan dapat diberikan dengan cara memberikan informasi yang dapat membantu remaja untuk membuka pikiran rasionalnya dalam mengambil segala sesuatu keputusan, khususnya yang terkait dengan seks. Hasil penelitian PKBI DIY di beberapa kota yaitu Medan, Jakarta, Yogyakarta, Surabaya, Bali dan Manado, bahwa angka kehamilan sebelum menikah pada remaja dan mencari pertolongan abortus terus meningkat. Perkiraan kabar berita harian menunjukkan bahwa setiap tahun ada 1 juta wanita Indonesia melakukan pengguguran kehamilan dan $50 \%$ berstatus belum menikah serta $10-15 \%$ diantaranya adalah remaja (Suriasumantri, 2010).

Berdasarkan hasil penelitian tersebut, kehamilan tidak diinginkan (unwanted pregnancy) pada remaja sudah seharusnya mendapat perhatian dari seluruh lapisan masyarakat, orangtua dan keluarga, guru dan seluruh anggota masyarakat sekolah, masyarakat sekitar, dan orang-orang terdekat. Kehamilan tidak diinginkan (unwanted pregnancy) dikalangan remaja khususnya siswa harusnya tidak terjadi, oleh karena itu penting adanya upaya pencegahan melalui pemberian informasi dan pelatihan bagi siswa untuk dapat menyikapi dengan baik teman sebayanya yang ingin berbagi. Oleh sebab itu siswa perlu dilatih untuk dapat menjadi konselor sebaya yang terampil dan berwawasan 
Diterbitkan oleh Lembaga Pengabdian kepada Masyarakat

Universitas Ahmad Dahlan Yogyakarta

luas tentang bahaya kehamilan tidak diinginkan (unwanted pregnancy). Sehingga untuk dapat mefasilitasi konselor sebaya dalam membantu mencegah terjadinya kehamilan tidak diinginkan (unwanted pregnancy) maka diperlukan wadah bagi layanan konseling sebaya atau disebut dengan peer counseling.

Program pengabdian masyarakat yang dilaksanakan dengan judul pelatihan peer counseling tentang kehamilan tidak diinginkan (unwanted pregnancy) di kalangan remaja tingkat sekolah menengah kejuruan merupakan program pengabdian masyarakat yang dilaksanakan dikecamatan Playen Gunung Kidul. Pemilihan lokasi pelaksanaan pengabdian di daerah Playen Gunung Kidul ini berdasarkan hasil survey pada bulan Februari 2017, bahwa di sekolah menengah kejuruan daerah Playen Gunung Kidul belum ada kegiatan pelatihan peer counseling tentang kehamilan tidak diinginkan (unwanted pregnancy). Pelaksanaan program pengabdian ini bertujuan untuk memberikan pemahaman, pengetahuan, dan melatih keterampilan peserta didik agar mampu memberikan layanan konseling bagi teman sebayanya.

\section{B. METODE}

Pengabdian masyarakat ini diberikan dengan menggunakan metode ceramah dan praktik atau demonstrasi. Subyek pengabdian merupakan siswa-siswi sekolah menengah kejuruan di kecamatan Playen Gunung Kidul yang berjumlah 70 peserta didik. Pelaksanaan pengabdian ini dilakukan selama 8 sesi pertemuan. Pada sesi pertama sampai ke empat fokus membahas terkait dengan teori tentang pemahaman peserta didik terhadap kehamilan tidak diinginkan (unwanted pregnancy) dan teori keterampilan peer counseling. Pada sesi ke lima sampai ke delapan berfokus pada praktik pemberian layanan peer counseling. Sebelum praktik dilaksanakan, fasilitator memberikan contoh terlebih dahulu pelaksanaan layanan peer counseling kepada peserta melalui tayangan video peer counseling. Selanjutnya dalam pelaksanaan praktik terdapat beberapa tahapan yang dilakukan oleh fasilitator, antara lain: (1) peserta didik diminta untuk membagi kelompok dengan masingmasing kelompok terdiri dari dua orang (berpasangan); (2) setiap kelompok diberi tema untuk dijadikan sebagai bahan permasalahan dalam praktik dan diminta untuk latihan dengan kelompoknya; (3) kelompok yang siap diminta untuk dapat manampilkan di depan peserta yang lain; (4) fasilitator dan peserta didik yang tidak tampil secara bersama-sama mengevaluasi praktik peer counseling sehingga dapat diketahui materi pelatihan mana yang telah dan belum dikuasai oleh peserta pelatihan, serta materi mana yang harus diperbaiki dan dikembangkan lagi.

\section{HASIL DAN PEMBAHASAN}

Pada proses perkembangan sosial remaja, kehadiran akan teman merupakan suatu kebutuhan yang sulit untuk dihindari. Berbagai kesempatan dan banyaknya waktu yang dihabiskan remaja dengan teman sebayanya seringkali menimbulkan berbagai macam problem yang tidak dapat dihindari, baik yang berhubungan langsung dengan teman sebaya atau yang menyangkut masalah pribadi. Remaja yang berada dalam kondisi tersebut memiliki potensi untuk bertahan dan berkembang. Ketika berada pada kondisi tersebut hanya sebagian remaja yang memanfaatkan dan bersedia berkonsultasi langsung dengan 
konselor ahli di sekolah. Siswa (remaja) cenderung menjadikan teman-teman mereka sebagai sumber pertama dalam mempertimbangkan pengambilan putusan pribadi. Remaja sering kali mencari sesama remaja yang memiliki perasaan sama, mencari teman yang mau mendengarkan, dan mencari teman yang mau menerima dan memahami dirinya. Untuk dapat menjadi teman yang mampu membuat nyaman dan dicari oleh sebayanya, remaja perlu memiliki kemampuan yang mampu memberikan daya tarik bagi teman sebayanya seperti kemampuan memahami suasana, tanggung jawab, dan harga diri (Suwarjo, 2008). Hal demikian dapat diperoleh jika remaja mampu dan memiliki kesempatan untuk saling menolong di antara sesama mereka.

Konseling sebaya (peer counseling) merupakan suatu wahana belajar remaja untuk dapat saling memperhatikan dan saling bantu satu sama lain. Konseling sebaya secara kuat menempatkan keterampilan-keterampilan komunikasi untuk memfasilitasi eksplorasi diri dan pembuatan keputusan. Konseling teman sebaya (peer counseling) merupakan pertolongan yang bersifat interpersonal, dilakukan oleh tenaga non profesional (peer counnselor) kepada konseli yang memiliki kesamaan dalam segi usia, pengalaman dan gaya hidup agar klien dapat menyelesaikan permasalahan yang dihadapi terutama permasalahan yang diangkat dalam pengabdian masyarakat yaitu kehamilan tidak diinginkan (unwanted pregnancy). Hasil pelaksanaan pengabdian pada masyarakat terlihat perubahan pemahaman peserta pelatihan terkait dengan pengetahuan kehamilan tidak diinginkan (unwanted pregnancy) baik penyebab dan dampak negatifnya dan keterampilan yang harus dimiliki peer counselor dalam melaksanakan layanan peer counseling. Beberapa materi yang diberikan pada pelatihan ini antara lain: (1) tugas perkembangan siswa di sekolah menengah; (2) kesehatan reproduksi remaja; (3) pergaulan remaja masa kini dan remaja islami bebas pacaran; (4) bahaya pornografi dan seks pranikah; (5) bahaya aborsi; (6) dampak menjadi orangtua di usia muda; (7) manajemen konflik; (8) teknik peer konseling.

Layanan peer counseling merupakan layanan yang melibatkan individu (remaja) untuk dapat memberikan layanan konseling kepada teman sebayanya. Hubungan yang terjalin antara remaja dengan teman sebaya merupakan suatu celah yang dapat digunakan untuk dapat memberikan pengaruh pada remaja. Kadangkala remaja secara tidak sadar telah dipengaruhi oleh teman sebayanya baik dalam berpikir, bersikap, maupun bertindak. Hasil penelitian Buhrmester (Santrock, 2009) menunjukkan pada masa remaja kedekatan hubungan dengan teman sebaya meningkat secara drastis, dan pada saat yang bersamaan kedekatan hubungan remaja dengan orang tua menurun secara drastis. Sejalan dengan hasil temuan tersebut, penelitian Nickerson \& Nagle (2005: 240) menunjukkan hasil bahwa pada masa remaja komunikasi dan kepercayaan terhadap orang tua berkurang, dan beralih kepada teman sebaya untuk memenuhi kebutuhan akan kelekatan (attachment). Kondisi tersebut wajar dialami oleh setiap remaja, sebab dalam proses perkembangannya, remaja berada pada masa pencarian identitas diri. Pada masa tersebut remaja akan lebih mudah terpengaruh dengan lingkungannya termasuk teman sebaya. Hal tersebut terjadi diprediksi karena remaja merasa senasib dengan teman sebayanya sehingga remaja merasa lebih nyaman jika berdekatan atau berbagi cerita dengan teman sebaya.

Pemberian layanan peer counseling tentu tidak dilakukan begitu saja oleh remaja, akan tetapi remaja tersebut sudah dibimbing dan dilatih oleh konselor ahli agar dapat 
menguasai beberapa keterampilan konseling yang nantinya akan diberikan kepada teman sebaya. Oleh karena itu konselor sebaya (peer counselor) bukanlah konselor profesional atau ahli konseling. Konselor sebaya adalah para siswa (remaja) terlatih yang memberikan bantuan kepada siswa/anak/remaja lain di bawah bimbingan konselor ahli. Agar dapat lebih jelas pola interaksi antara konselor ahli, konselor sebaya, dan konseli sebaya dapat dilihat pada gambar berikut ini.

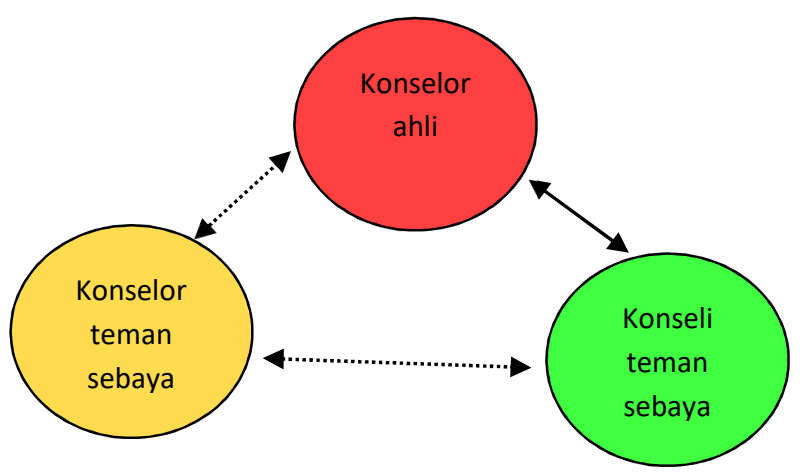

Gambar 1. Interaksi Triadik antara Konselor Ahli, Konselor Teman Sebaya, dengan Konseli Teman Sebaya (Suwarjo, 2008)

Hubungan antar tiga jaringan kerja (konselor ahli, konselor sebaya, konseli sebaya) tersebut juga dapat manambah nilai positif yakni mapu memperbaiki atau meningkatkan iklim sosial dan dapat menjadi jembatan penghubung antara konselor profesional dengan para siswa (remaja) yang tidak sempat atau tidak bersedia berjumpa dengan konselor.

Pada pelatihan peer counseling ini terdapat beberapa materi keterampilan dasar konseling yang diberikan pada peserta, antara lain: attending, emphatizing, summarizing, questioning, genuineness, asertivenes, confrontation, dan problem solving. Berbagai macam keterampilan konseling tersebut diberikan kepada peserta sebagai calon peer counselor agar dapat menjalin komunikasi interpersonal dengan baik. Melalui keterampilan konseling memungkinkan remaja untuk dapat memberikan layanan peer counseling bagi konseli sebaya deengan baik pula. Pada pelatihan ini, keterampilan konseling diberikan bagi calon peer counselor dengan tujuan khusus agar dapat membantu teman sebaya yang mengalami permasalahan seputar pengetahuan unwanted pregnancy oleh teman sebaya yang belum memahami dan membutuhkan bantuan dari peer counselor.

Peer counselor diharapkan dapat menjadi sahabat baik bagi teman sebaya dan diharapkan dapat memanfaatkan keterampilan konseling yang telah dilatihkan, minimal mampu menjadi pendengar aktif bagi teman sebayanya. Menjadi pendengar aktif berarti mampu mendengarkan cerita teman sebaya dengan penuh perhatian, memperhatikan konten cerita teman, mampu menunjukkan ketertarikan terhadap cerita teman, mampu menangkap ungkapan pikiran dan emosi di balik ekspresi verbal maupun non verbal, mampu mengekspresikan pemahaman dan penerimaan secara tulus dan empatik kepada teman sebayanya. Menjadi peer counselor memungkinkan remaja untuk dapat membantu membantu teman sebaya dalam menyelesaikan permasalahan, namun ketika peer counselor merasa tidak mampu atau tidak berkompeten tdalam penyelesaian masalah teman sebaya 
maka diharapkan dapat mengalihtangankan kepada konselor ahli. Sehingga model interaksi triadik pada gambar 1 tetap dapat berjalan sebagaimana mestinya.

\section{KESIMPULAN}

Pengabdian Masyarakat yang dilaksanakan di sekolah menengah kejuruan di kecamatan Playen Gunung Kidul memberikan kontribusi pengetahuan kehamilan tidak diinginkan (unwanted pregnancy) bagi remaja dan melatih kemampuan remaja untuk dapat menguasai keterampilan konseling sehingga dapat memberikan rasa nyaman, menjadi pendengar yang baik, mampu berempati, dan mampu mengarahkan teman sebaya untuk dapat menyelesaikan permasalahan dan membuat keputusan terkait dengan permasalahan yang dihadapi, dalam hal ini terkait dengan pengetahuan kehamilan tidak diinginkan (unwanted pregnancy). Tujuan akhir dari pelaksanaan pegabdian melalui pemberian pemahaman dan pelatihan ini agar remaja dapat meningkatkan pemahaman pengetahuan kehamilan tidak diinginkan (unwanted pregnancy) dan menguasai keterampilan konseling yang berguna untuk membantu teman sebaya yang sedang menghadapi permasalahan.

\section{DAFTAR PUSTAKA}

Antara news. (20110). Mendiknas Tidak Setuju Pendidikan Seks di Sekolah. http://www.antaranews.com/berita/207199/mendiknas-tidak-setuju-pendidikanseks-di-sekolah; diakses Selasa, 29 Agustus 2017.

Nickerson, A.B. \& Nagle, R.J. (2005). Parent and Peer Attachment in Late Childhood and Early Adolescence. Journal of Early Adolescence. 25. (2). 223-249. Sage Publications.

Santrock, J.W. (2009). Life-Span Development Twelfth Edition. Boston: McGraw-Hill Companies.

Suriasumantri. (2010). Akibat Seks Bebas. http: //veldinor23. student. umm.ac.id/ download-as-pdf/ umm_blog_article_49. pdf: diakses Kamis, 27 Desember 2012.

Suwarjo. (2008). Pedoman Koseling Teman Sebaya untuk Pengembangan Resiliensi. Universitas Negeri Yogyakarta. 